\title{
Visceral Leishmaniasis-Malaria Coinfection and Their Associated Factors in Patients Attending Metema Hospital, Northwest Ethiopia: Suggestion for Integrated Vector Management
}

\author{
Getachew Ferede, ${ }^{1}$ Ermias Diro, ${ }^{2}$ Sisay Getie, ${ }_{1}^{1}$ Gebeyaw Getnet, ${ }^{1}$ Yegnasew Takele, ${ }^{3}$ \\ Anteneh Amsalu, ${ }^{4}$ and Yitayih Wondimeneh ${ }^{1}$ \\ ${ }^{1}$ College of Medicine and Health Sciences, School of Biomedical and Laboratory Sciences, Department of Medical Parasitology, \\ University of Gondar, P.O. Box 196, Gondar, Ethiopia \\ ${ }^{2}$ College of Medicine and Health Sciences, School of Medicine, Department of Internal Medicine, University of Gondar, P.O. Box 196, \\ Gondar, Ethiopia \\ ${ }^{3}$ Leishmaniasis Research and Treatment Center, University of Gondar, Gondar, Ethiopia \\ ${ }^{4}$ College of Medicine and Health Sciences, School of Biomedical and Laboratory Sciences, Department of Medical Microbiology, \\ University of Gondar, P.O. Box 196, Gondar, Ethiopia
}

Correspondence should be addressed to Getachew Ferede; get29f@gmail.com

Received 18 April 2017; Revised 24 July 2017; Accepted 31 July 2017; Published 28 August 2017

Academic Editor: Rana Chattopadhyay

Copyright (C) 2017 Getachew Ferede et al. This is an open access article distributed under the Creative Commons Attribution License, which permits unrestricted use, distribution, and reproduction in any medium, provided the original work is properly cited.

Background. Despite high prevalence of visceral leishmaniasis and malaria in the study area, their coinfection remains unknown. Therefore, this study was aimed to document VL-malaria coinfections and their associated factors. Methods. A cross-sectional study was conducted among clinical suspected VL patients attending Metema hospital, Northwest Ethiopia, from January 2014 to June 2014. Blood sample was tested by rk39 antigen-based DiaMed IT-Leish dipstick and Giemsa stain microscopic examination of thick and thin blood smears for malaria detection was performed. Result. A total of $384 \mathrm{VL}$ suspected patients were included in the study. Out of these, the prevalence of VL was 83 (21.6\%) while the prevalence of malaria was 45 (11.7\%). Of malaria cases, 40 (89\%) were positive for P. falciparum and 5 (11\%) positive for P. vivax. The overall prevalence of VL-malaria coinfection was 16 (4.2\%). One-hundred eighty (46.9\%) study participants have history of travel. Of these, 10 (5.6\%) have VL-malaria coinfections. Age less than 5 years was associated with VL-malaria coinfection. Conclusion. This study highlights the importance of performing malaria screening amongst VL patients living in malaria-endemic areas, particularly in patients under five years.

\section{Background}

Leishmaniasis and malaria are among the most important six diseases on the World Health Organization (WHO) or Tropical Disease Research list. There are 2 million new cases of Leishmaniasis diagnosed every year [1]. As for malaria, 300-660 million people become infected yearly with the malignant Plasmodium falciparum, and 200-300 children are dying every hour from this disease $[2,3]$. According to the world malaria report 2016, there were about 212 million cases of malaria and 429,000 deaths [4].
Visceral leishmaniasis (VL) is the phlebotomine sand flies borne disease caused by an intracellular protozoan parasite of the Leishmania donovani complex [5], while malaria is Anopheles mosquito borne disease caused by an intracellular protozoan parasite of Plasmodium species [6]. Usually, the transmission of both parasites occurs when the female insect takes a blood meal. Measures to combat these two diseases usually aimed at interrupting the life-cycle of the parasite by destroying the parasite or its vector. Destroying the parasite could be achieved by vaccination or treatment. Destroying the vector could be achieved by many ways such 
as introducing an enemy of the vector to the environment, using the sterile male technique, destroying the habitat of the vector, or spraying pesticides [7].

Visceral leishmaniasis and malaria are the two major lifethreatening parasitic diseases that still remain a serious public health problem, particularly in endemic areas $[8,9]$. Differential diagnosis of VL often includes malaria among other febrile splenomegalies, due to its clinical overlap. Malaria, in fact, is widespread in tropical and subtropical regions of the world, where it accounts for more than 250 million cases annually, the vast majority of which occurs among children under 5 years old [10]. Transmission can occur throughout the year or be seasonal, depending on the region [11]. In the latter case, transmission seasons for VL and malaria may not coincide, but the two diseases still overlap, due to the longer incubation period of VL. The overlap in disease distribution suggests the two diseases could cooccur in the same host.

Visceral leishmaniasis and malaria coinfections have been reported across various African and Asian countries, with the prevalence among VL patients ranging from $20.8 \%$ and $6.4 \%$ in Uganda $[12,13]$ to $10.7 \%$ in Sudan [14] and $1.2 \%$ in Bangladesh [15] and a rate of 5.9\% among Indian patients with fever and splenomegaly [16], with the exception of the case-reports [17-20], whose evidence remains anecdotal. Despite high prevalence of the VL [21] and malaria [22] in the study area, their coinfection is unknown. Therefore, this study was designed to document the prevalence of VL-malaria coinfection and their associated factors among patients attending Metema hospital.

\section{Materials and Methods}

2.1. Study Area and Period. This study was conducted at Metema hospital from January 2014 to June 2014. Metema is a town in Northwestern Ethiopia, on the border with Sudan. This town is located in the North Gondar Administrative Zone, Amhara region, $897 \mathrm{~km}$ North of Addis Ababa and $197 \mathrm{~km}$ from the ancient city of Gondar, and it has a latitude and longitude of $12^{\circ} 58^{\prime} \mathrm{N} 36^{\circ} 12^{\prime} \mathrm{E}$ with an elevation of 685 meters above sea level. This area is malarious and has cases of VL.

2.2. Study Design, Study Population, and Sampling Technique. A cross-sectional study was carried out at Metema hospital to determine VL-malaria coinfection among all clinically suspected VL patients. Visceral leishmaniasis suspected patients who have taken treatment for malaria and/or VL for the last two weeks were excluded from the study. Visceral leishmaniasis suspects are defined as those individuals who develop clinical evidence of infection usually have fever, loss of appetite (anorexia), weight loss, fatigue, anemia, enlargement (swelling) of the spleen and liver, and abnormal blood tests [23].

2.3. Data Collection and Processing. Well-structured questionnaire was prepared in English version by the research team. It was translated later into the local language, Amharic. The questionnaire addresses patients' sociodemographic information and associated factors. A pretest was conducted among five percent of the total sample size by trained data collectors and any ambiguous questions and repetitive ideas were corrected. Additional response categories were added based on the pretest findings.

2.4. Parasitological Techniques. After interviewing the patients, fresh peripheral whole blood sample was tested by the rk39 ICT with sensitivity of $100 \%$ and specificity of 98\% [24] for diagnosis of VL, and Giemsa stain microscopic examination of thick and thin blood smears for malaria detection and species differentiation was performed systematically.

2.5. Data Analysis. Data were entered and analyzed using SPSS version 20 software. The Pearson Chi-square test was employed to examine associated factors with the coinfection. $P$ value $<0.05$ was considered statistically significant.

2.6. Ethical Consideration. Ethical clearance was obtained from Institutional Review Board of University of Gondar. Written informed consent was obtained from each of the volunteer study subjects or guardian of children. Patient information was anonymized and deidentified prior to analysis. Positive results were given for physicians working in the hospital for treatment according to the national treatment guideline.

\section{Results}

3.1. Sociodemographic Characteristics. A total of $384 \mathrm{VL}$ suspected participants were included in this study. Out of these, 334 (87\%) were males. The mean (standard deviation) age was 28.1 (11.8) years (ranging from 2 to 78 years). Majority $227(59.1 \%)$ of the study participants were in the age group of 15-29 years old. Among the study groups, 230 (59.9\%) were illiterate and 267 (69.5\%) were farmers followed by $54(14.1 \%)$ daily laborers. The majority of study participants 234 (60.9\%) were from rural residents (Table 1).

3.2. Visceral Leishmaniasis-Malaria Coinfection and Sociodemographic Characteristics. Out of the total VL suspected cases $2(33.3 \%)$ VL-malaria coinfections were found in the age groups of $<5$ years followed by 9 (4\%) within $15-29$ years old $(P=0.004)$. Visceral leishmaniasis-malaria coinfection by gender showed that $15(4.5 \%)$ of males were coinfected by VLmalaria. Individuals who live in the urban 8 (5.3\%) and rural $8(3.4 \%)$ were coinfected with VL-malaria. 5 daily laborers (9.3\%) were coinfected with VL-malaria (Table 2).

3.3. Prevalence of VL-Malaria Coinfection. Out of the total VL suspected patients, the overall prevalence of VL-malaria coinfection was $16(4.2 \%)$. The prevalence of VL was 83 $(21.6 \%)$ while the prevalence of malaria was $45(11.7 \%)$ (Table 3). Of the malaria positive patients, 40 (89\%) were positive for $P$. falciparum and 5 (11\%) were positive for $P$. vivax (Figure 1).

3.4. Associated Factors for VL-Malaria Coinfection. From the total study participants, 292 (76\%) were used bed nets. Of these, $13(4.5 \%)$ patients were VL-malaria coinfected. Most of the study participants, 217 (56.5\%) sleep inside home. One 
TABLE 1: Sociodemographic characteristics of the study participants at Metema hospital, Northwest Ethiopia, 2014.

\begin{tabular}{|c|c|c|c|}
\hline Characteristic & & Frequency & Percentage \\
\hline \multirow{5}{*}{ Age (years) } & $<5$ & 6 & 1.6 \\
\hline & $5-14$ & 20 & 5.2 \\
\hline & $15-29$ & 227 & 59.1 \\
\hline & $30-44$ & 99 & 25.8 \\
\hline & $\geq 45$ & 32 & 8.3 \\
\hline \multirow{2}{*}{ Gender } & Male & 334 & 87.0 \\
\hline & Female & 50 & 13.0 \\
\hline \multirow{2}{*}{ Residence } & Rural & 234 & 60.9 \\
\hline & Urban & 150 & 39.1 \\
\hline \multirow{7}{*}{ Occupational status } & Farmer & 267 & 69.5 \\
\hline & Merchant & 12 & 3.1 \\
\hline & Driver & 2 & 0.5 \\
\hline & Civil servant & 12 & 3.1 \\
\hline & Daily laborer & 54 & 14.1 \\
\hline & Housewife & 18 & 4.7 \\
\hline & Student & 19 & 4.9 \\
\hline \multirow{5}{*}{ Educational status } & Illiterate & 230 & 59.9 \\
\hline & Only read and write & 85 & 22.1 \\
\hline & Elementary school & 45 & 11.7 \\
\hline & High school & 21 & 5.5 \\
\hline & College/universities & 3 & 0.8 \\
\hline
\end{tabular}

TABLE 2: Sociodemographic characteristics of the study participants in relation to VL-malaria coinfection at Metema Hospital, Northwest Ethiopia, 2014.

\begin{tabular}{|c|c|c|c|c|}
\hline \multirow[b]{2}{*}{ Variables } & & \multicolumn{2}{|c|}{ VL suspected cases } & \multirow[b]{2}{*}{$P$ value } \\
\hline & & $\begin{array}{l}\text { Not VL-malaria } \\
\text { coinfected }(\%)\end{array}$ & $\begin{array}{c}\text { VL-malaria } \\
\text { coinfected (\%) }\end{array}$ & \\
\hline \multirow{5}{*}{ Age } & $<5$ & $4(66.7)$ & $2(33.3)$ & \multirow{5}{*}{0.004} \\
\hline & $5-14$ & $20(100)$ & $0(0)$ & \\
\hline & $15-29$ & $218(96.0)$ & $9(4.0)$ & \\
\hline & $30-44$ & $94(95.0)$ & $5(5.0)$ & \\
\hline & $\geq 45$ & $32(100)$ & $0(0)$ & \\
\hline \multirow{2}{*}{ Gender } & Male & $319(95.5)$ & $15(4.5)$ & \multirow{2}{*}{0.411} \\
\hline & Female & $49(98.0)$ & $1(2.0)$ & \\
\hline \multirow{2}{*}{ Residence } & Rural & $226(96.6)$ & $8(3.4)$ & \multirow{2}{*}{0.360} \\
\hline & Urban & $142(94.7)$ & $8(5.3)$ & \\
\hline \multirow{7}{*}{ Occupation status } & Farmer & 257 (96.3) & $10(3.7)$ & \multirow{7}{*}{0.384} \\
\hline & Merchant & $11(91.7)$ & $1(8.3)$ & \\
\hline & Driver & $2(100)$ & $0(0)$ & \\
\hline & Civil servant & $12(100)$ & $0(0)$ & \\
\hline & Daily laborer & $49(90.7)$ & $5(9.3)$ & \\
\hline & Housewife & $18(100)$ & $0(0)$ & \\
\hline & Student & $19(100)$ & $0(0)$ & \\
\hline \multirow{5}{*}{ Educational status } & Illiterate & $219(95.2)$ & $11(4.8)$ & \multirow{5}{*}{0.181} \\
\hline & Only read and write & $85(100)$ & $0(0)$ & \\
\hline & Elementary school & $42(93.3)$ & $3(6.7)$ & \\
\hline & High school & $19(90.5)$ & $2(9.5)$ & \\
\hline & Higher education & $3(100)$ & $0(0)$ & \\
\hline
\end{tabular}




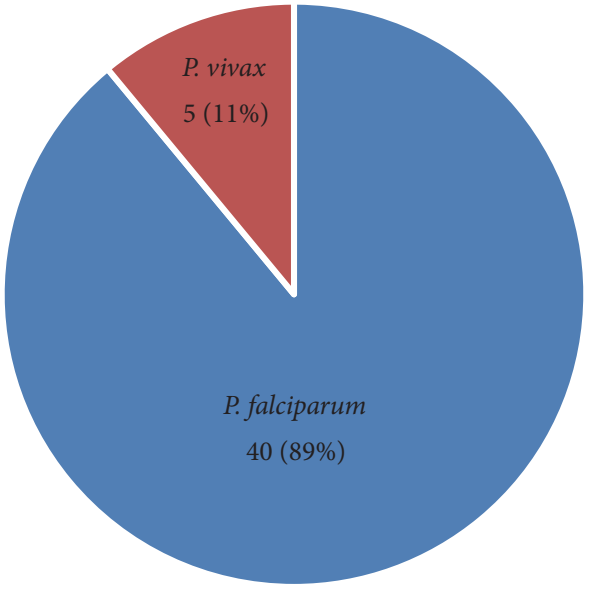

FIGURE 1: Frequency of Plasmodium species at Metema hospital, Northwest Ethiopia, 2014.

TABLE 3: Prevalence of VL, malaria, and their coinfection among VL suspected patients at Metema hospital, Northwest Ethiopia, 2014.

\begin{tabular}{lccc}
\hline Variables and result & VL (\%) & Malaria (\%) & $\begin{array}{c}\text { VL-malaria } \\
\text { coinfection (\%) }\end{array}$ \\
\hline Negative & $301(78.4)$ & $339(88.3)$ & $368(95.8)$ \\
Positive & $83(21.6)$ & $45(11.7)$ & $16(4.2)$ \\
\hline
\end{tabular}

hundred eighty (46.9\%) study participants have history of travel from Metema to any region of Ethiopia and vice versa. Of these, 10 (5.6\%) of them have VL-malaria coinfection. All study variables did not show statistical significance (Table 4).

\section{Discussion}

Visceral leishmaniasis and malaria coinfection may exist in endemic areas due to similarity in clinical manifestations of the two diseases but their coinfection has been poorly investigated. In the present study, the overall prevalence of VL-malaria coinfection was $4.2 \%$. This is in agreement with the study which is conducted in India 5.9\% among Indian patients with fever and splenomegaly [16]. However, this prevalence was lower as compared to study reported in Uganda 19\% [25]. This variation might be due to difference in the $\mathrm{VL}$ and malaria prevalence which is $21.6 \%$ and $11.7 \%$ in this study and 57\% and 31\% in Uganda, respectively [25].

In this study, prevalence of VL-malaria coinfection was nonsignificantly higher in males than females. A similar finding was also reported in other studies [25-27]. The higher prevalence rate might be due to the fact that males engage in activities which make them more prone to infective mosquito and sand fly bites as compared to females who are mostly at home and protected from such infective bites.

Visceral leishmaniasis has been a major health problem in North Gondar, especially in lowlands of Metema and Humera plains, which are important endemic foci in Northwest of Ethiopia [28]. In the present study, its prevalence was $21.6 \%$, which was consistent with the other study done in the same study area, $22.6 \%$ [21], however, lower than the study in other areas of Ethiopia which was reported as 39.1\% [29]. The variation might be due to heterogeneity of the vectors. Following agricultural development in the region, a large number of labor migrants from the different areas were moved to the endemic areas for crop harvesting. This led to outbreaks of VL, in many areas in the country which resulted in high morbidity and mortality [30].

Malaria is also one of the most public health problems in Ethiopia. The total land mass of the country is regarded as malarious and about $68 \%$ of the total population is at risk of malaria infection [31]. In this study, the prevalence of malaria was $11.7 \%$, which is relatively lower than previous study done in the same study area (17\%) [22]. The variation might be due to difference in study participants. The predominant Plasmodium species detected was P. falciparum. This was in agreement with other previous studies [22, 32, 33].

Visceral leishmaniasis-malaria coinfection was significantly higher in patients with the age groups of less than five years $(P=0.004)$ followed by patients in the age groups of fifteen to twenty-nine years. This indicates that children less than five years old are prone to acquire VLmalaria coinfections which might be associated with their low immune system. On the other hand, high prevalence of VL-malaria coinfection within fifteen to twenty-nine years old might be associated with their daily activities. Farming is extensive in Metema due to the fact that young daily laborers move to Metema from different areas for application of herbicide and for gathering of crops. Because of high temperature in this area, daily activities are accomplished especially during night. This may expose them to the bite of mosquitoes and sand fly which means a more concentrated effort should be given to educate these age groups about this disease and its vector.

In this study, majority of study subjects use their bed nets. However, the prevalence of VL-malaria coinfection was high in these subjects. This might be due to improper and infrequent use of their bed net or it might be due to lack of impregnating their bed nets regularly. In the study area most of study participants who were coinfected with VL-malaria were daily laborers followed by merchants. This might be associated with their daily activities which may expose them for vector bite.

This study is limited to the data obtained from the VL suspected patients, which may reduce the prevalence of malaria. Moreover, this study for VL diagnosis depends only on serological tests. There is no microscopically confirmed parasitological data for VL. To fill all these gaps, there is a need for further study including all febrile patients with different study design.

In conclusion, this study tries to see VL-malaria coinfection for the first time and found $4.2 \%$ coinfection rate. A significantly higher number of VL-malaria coinfections were showed in study subjects whose age was less than five years old. Based on these findings, we recommend that malaria screening be implemented for all VL patients who live in malaria-endemic areas in order to promptly initiate antimalarial drug treatment. Moreover, to minimize the disease burden, health planners and administrators need to 
TABLE 4: Associated factors of VL-malaria coinfection at Metema hospital, Northwest Ethiopia, 2014.

\begin{tabular}{|c|c|c|c|}
\hline \multirow{2}{*}{ Variables } & \multicolumn{2}{|c|}{ VL suspected cases } & \multirow{2}{*}{$P$ value } \\
\hline & Not VL-malaria coinfected (\%) & VL-malaria coinfected $(\%)$ & \\
\hline \multicolumn{4}{|l|}{ Bed net use } \\
\hline Yes & $279(95.5)$ & $13(4.5)$ & \multirow{2}{*}{0.618} \\
\hline No & $89(96.7)$ & $3(3.3)$ & \\
\hline \multicolumn{4}{|l|}{ Sleep usually } \\
\hline Inside home & $209(96.3)$ & $8(3.7)$ & \multirow{2}{*}{0.592} \\
\hline Outside home & $158(95.2)$ & $8(4.8)$ & \\
\hline \multicolumn{4}{|l|}{ Lived in Metema } \\
\hline Less than 6 months & $23(95.8)$ & $1(4.2)$ & \multirow{2}{*}{0.999} \\
\hline More than 6 months & $345(95.8)$ & $15(4.2)$ & \\
\hline \multicolumn{4}{|l|}{ History of travel } \\
\hline Yes & $170(94.4)$ & $10(5.6)$ & \multirow{2}{*}{0.201} \\
\hline No & $198(97.0)$ & $6(3.0)$ & \\
\hline \multicolumn{4}{|c|}{ Seasonal migrant laborers } \\
\hline Yes & $152(96.2)$ & $6(3.8)$ & \multirow{2}{*}{0.762} \\
\hline No & $216(95.6)$ & $10(4.4)$ & \\
\hline
\end{tabular}

give intensive health education to increase the community awareness about the two diseases' prevention and control strategies.

\section{Conflicts of Interest}

The authors declared that they have no conflicts of interest.

\section{Authors' Contributions}

Getachew Ferede participated in conception and design of the study, data collection and analysis, interpretation of the findings, drafting the paper, and the write-up. Ermias Diro, Sisay Getie, Gebeyaw Getnet, and Yegnasew Takele participated in conception and design of the study and interpretations of the findings and reviewed the manuscript. Yitayih Wondimeneh and Anteneh Amsalu participated in conception and design of the study, data analysis, and interpretations of the findings and reviewed manuscript. All authors reviewed and approved the final paper.

\section{Acknowledgments}

The authors would like to acknowledge University of Gondar for financial support and they also thank all the study participants and all Metema hospital laboratory staffs for their cooperation during data collection.

\section{References}

[1] R. W. Ashford, P. Desjeux, and P. deRaadt, "Estimation of population at risk of infection and number of cases of Leishmaniasis," Parasitology Today, vol. 8, no. 3, pp. 104-105, 1992.

[2] R. Snow, M. Craig, C. Newton, and R. Stekete, The Public Health Burden of Plasmodium Falciparum Malaria in Africa: Deriving the Numbers, Forgarty International Center, National Institute of Health, Bethesda, MD, USA, 2003.
[3] R. W. Snow, C. A. Guerra, A. M. Noor, H. Y. Myint, and S. I. Hay, "The global distribution of clinical episodes of Plasmodium falciparum malaria," Nature, vol. 434, no. 7030, pp. 214-217, 2005.

[4] World Health Organization. World Malaria Report 2016. http://apps.who.int/iris/bitstream/10665/252038/1/9789241511711eng.pdf.

[5] J. Lukeš, I. L. Mauricio, G. Schönian et al., "Evolutionary and geographical history of the Leishmania donovani complex with a revision of current taxonomy," Proceedings of the National Academy of Sciences of the United States of America, vol. 104, no. 22, pp. 9375-9380, 2007.

[6] H. Gilles, The Malaria Parasites, Edward Arnold: BruceChwatt's Essential Malariology, London, UK, 3rd edition, 1993.

[7] Tech. Rep., World Health Organization: Vector Control for Malaria and Other Mosquito Born Diseases: Technical Report Series, Geneva, 1995.

[8] P. Desjeux, "Leishmaniasis: current situation and new perspectives," Comparative Immunology, Microbiology and Infectious Diseases, vol. 27, no. 5, pp. 305-318, 2004.

[9] World health Organization; Malaria fact sheet. [cited 2016]; Available from: http://www.who.int/ith/diseases/malaria/en/.

[10] WHO: World Malaria Report, World Health organization, Geneva, Switzerland, 2010.

[11] R. E. L. Paul, M. Diallo, and P. T. Brey, "Mosquitoes and transmission of malaria parasites - Not just vectors," Malaria Journal, vol. 3, article no. 39, 2004.

[12] Y. Mueller, D. B. Mbulamberi, P. Odermatt, A. Hoffmann, L. Loutan, and F. Chappuis, "Risk factors for in-hospital mortality of visceral leishmaniasis patients in eastern Uganda," Tropical Medicine and International Health, vol. 14, no. 8, pp. 910-917, 2009.

[13] J. H. Kolaczinski, R. Reithinger, D. T. Worku et al., "Risk factors of visceral leishmaniasis in East Africa: A case-control study in Pokot territory of Kenya and Uganda," International Journal of Epidemiology, vol. 37, no. 2, pp. 344-352, 2008.

[14] P. Beer, A. Harith, L. Deng, S. Semiao-Santos, and B. Chantal, "A killing disease epidemic among displaced sudanese population 
identified as visceral leishmaniasis," The American Journal of Tropical Medicine and Hygiene, vol. 44, pp. 283-289, 1991.

[15] C. Sarker, K. Chowdhury, N. Siddiqui, M. Jamal, and S. Rahman, "Clinical profile of kala-azar in adults: as seen in Mymensingh medical college hospital, Mymensingh, Bangladesh," Mymensingh Medical Journal, vol. 12, pp. 41-44, 2003.

[16] A. Nandy, M. Addy, S. K. Guha, A. K. Maji, H. M. Chauahuri, and P. Chatterjee, "Co-existent kala-azar and malaria in India," Transactions of the Royal Society of Tropical Medicine and Hygiene, vol. 89, no. 5, p. 516, 1995.

[17] K. Saha, D. Chattopadhya, and D. Kulpati, "Concomitant kalaazar, malaria and progressive unstable indeterminate leprosy in an 8-year-old child," Journal of Tropical Pediatrics, vol. 44, pp. 247-248, 1998.

[18] S. Sah, S. Sharma, and S. Rani, "Kala azar associated with malaria," Archives of Pathology \& Laboratory Medicine, vol. 126, p. 383, 2002.

[19] J. Woodrow, J. Hartzell, J. Czarnik, D. Brett-Major, and G. Wortmann, "Cutaneous and presumed visceral leishmaniasis in a soldier deployed to Afghanistan," International Journal of General Medicine, vol. 8, article 43, 2006.

[20] A. K. Ab Rahman and F. H. Abdullah, "Visceral leishmaniasis (kala-azar) and malaria coinfection in an immigrant in the state of Terengganu, Malaysia: A case report," Journal of Microbiology, Immunology and Infection, vol. 44, no. 1, pp. 72-76, 2011.

[21] S. Yeromenesh, W. Yitayih, W. Habtamu, and F. Getachew, "Trend analysis of visceral leishmaniasis in Metema Hospital Northwest, Ethiopia," Journal of Epidemiology and Public Health Reviews, vol. 1, pp. 2471-8211, 2016.

[22] F. Getachew, W. Abiyu, G. Alemtegna, A. Ali, H. Tarekegn, A. Yenus et al., "Prevalence of malaria from blood smears examination: a seven-year retrospective study from Metema Hospital, Northwest Ethiopia," Malaria Research and Treatment, vol. 2013, Article ID 704730, 5 pages, 2013.

[23] M. Siddig, H. Ghalib, D. Shillington, E. Petersen, and S. Khidir, "Visceral leishmaniasis in Sudan. Clinical features," Tropical and Geographical Medicine, vol. 42, pp. 107-112, 1990.

[24] S. Sundar, S. G. Reed, V. P. Singh, P. C. K. Kumar, and H. W. Murray, "Rapid accurate field diagnosis of Indian visceral leishmaniasis," Lancet, vol. 351, no. 9102, pp. 563-565, 1998.

[25] E. van den Bogaart, M. M. Z. Berkhout, E. R. Adams et al., "Prevalence, features and risk factors for malaria co-infections amongst visceral leishmaniasis patients from Amudat hospital, Uganda," PLoS Neglected Tropical Diseases, vol. 6, no. 4, Article ID e1617, 2012.

[26] S. Bashaye, N. Nombela, and D. Argaw, "Risk factors for visceral leishmaniasis in a new epidemic site in Amhara region, Ethiopia," The American Journal of Tropical Medicine and Hygiene, vol. 81, pp. 34-39, 2009.

[27] B. Bucheton, M. M. Kheir, S. H. El-Safi et al., "The interplay between environmental and host factors during an outbreak of visceral leishmaniasis in eastern Sudan," Microbes and Infection, vol. 4, no. 14, pp. 1449-1457, 2002.

[28] A. Hailu and D. Frommel, "Leishmaniasis in Ethiopia," in The Ecology of Health and Disease in Ethiopia, H. Kloos and Z. A. Zein, Eds., pp. 375-388, Westview Press, Boulder, Colo, USA, 1993.

[29] Y. Wondimeneh, Y. Takele, A. Atnafu, G. Ferede, and D. Muluye, "Trend analysis of visceral leishmaniasis at Addis Zemen health center, northwest Ethiopia," BioMed Research International, vol. 2014, Article ID 545393, 2014.
[30] D. Abyot, K. Solomon, and Andargachew., Module on Leishmaniasis for the Ethiopian Health Center Team, Debub Universit, Ethiopia, 2005.

[31] FMoH, National Five Year Strategic Plan for Malaria Prevention and Control in Ethiopia, 2006-2010, Ministry of Health, Addis Ababa, Ethiopia, 2006.

[32] Federal Republic of Ethiopia Ministry of Health,National Guide Lines, Federal Republic of Ethiopia Ministry of Health, Addis Abeba, Ethiopia, 3rd edition, 2012.

[33] K. Karunamoorthi and M. Bekele, "Prevalence of malaria from peripheral blood smears examination: a 1-year retrospective study from the Serbo Health Center, Kersa Woreda, Ethiopia," Journal of Infection and Public Health, vol. 2, no. 4, pp. 171-176, 2009. 


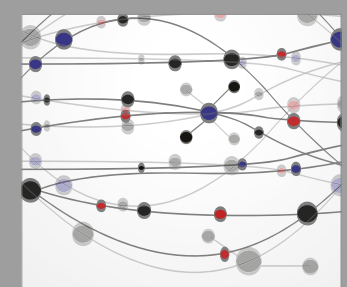

The Scientific World Journal
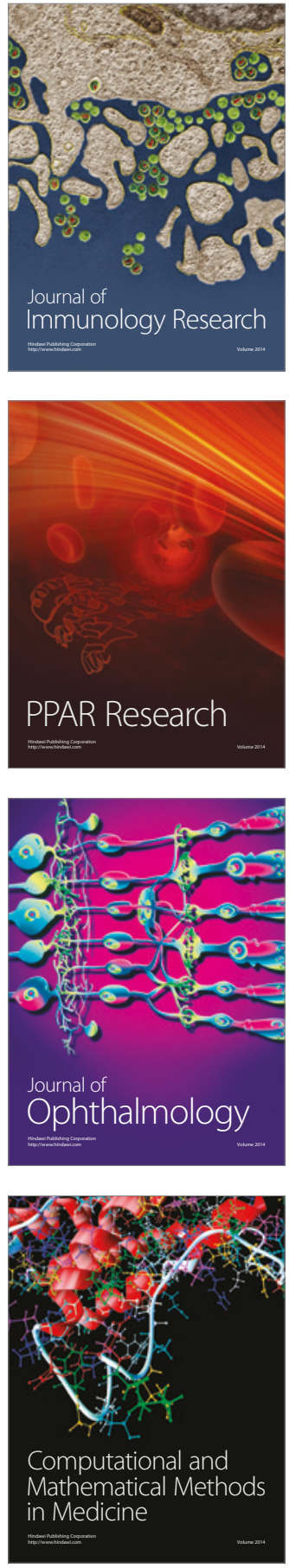

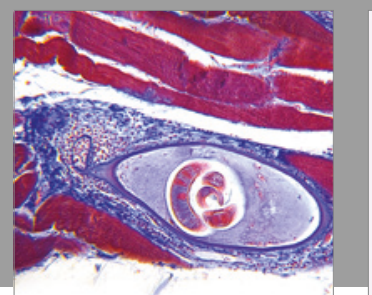

Gastroenterology Research and Practice
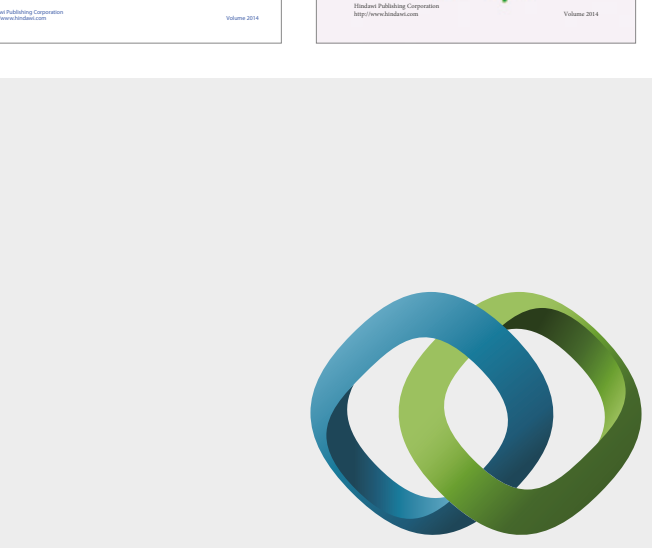

\section{Hindawi}

Submit your manuscripts at

https://www.hindawi.com
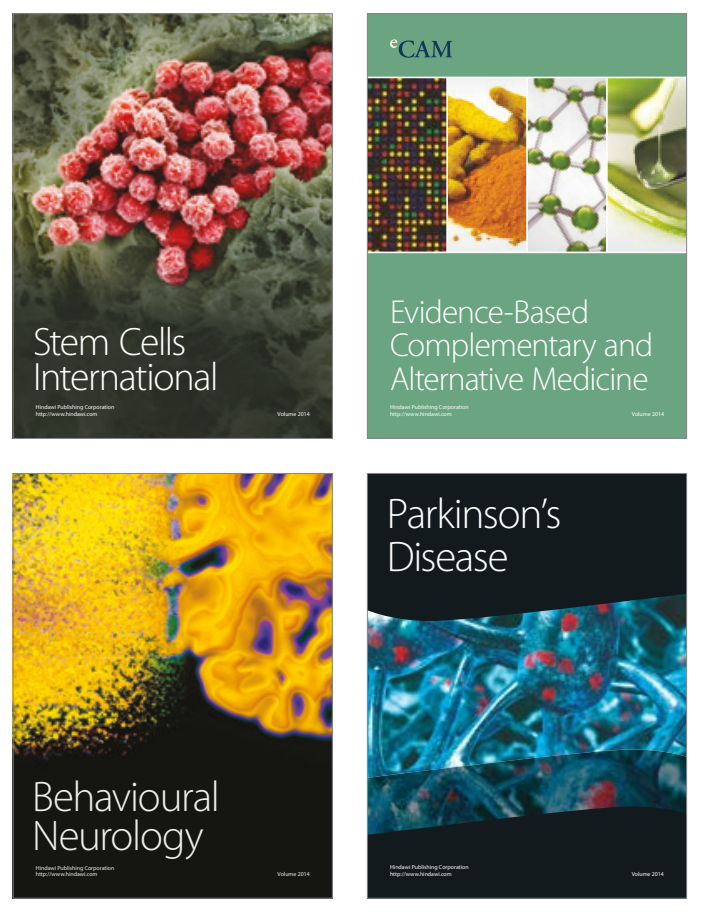
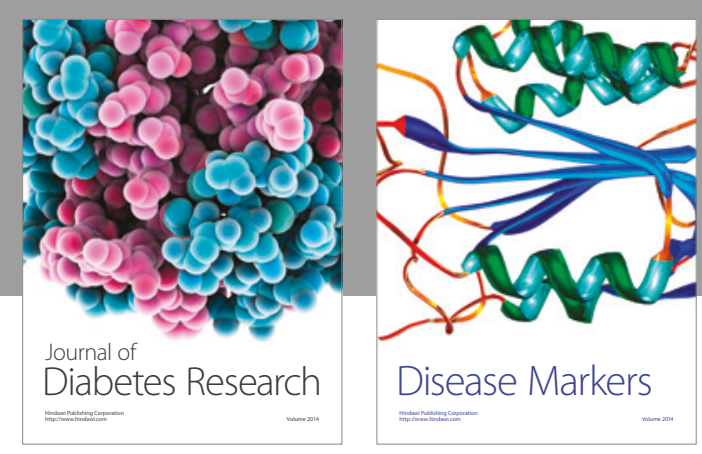

Disease Markers
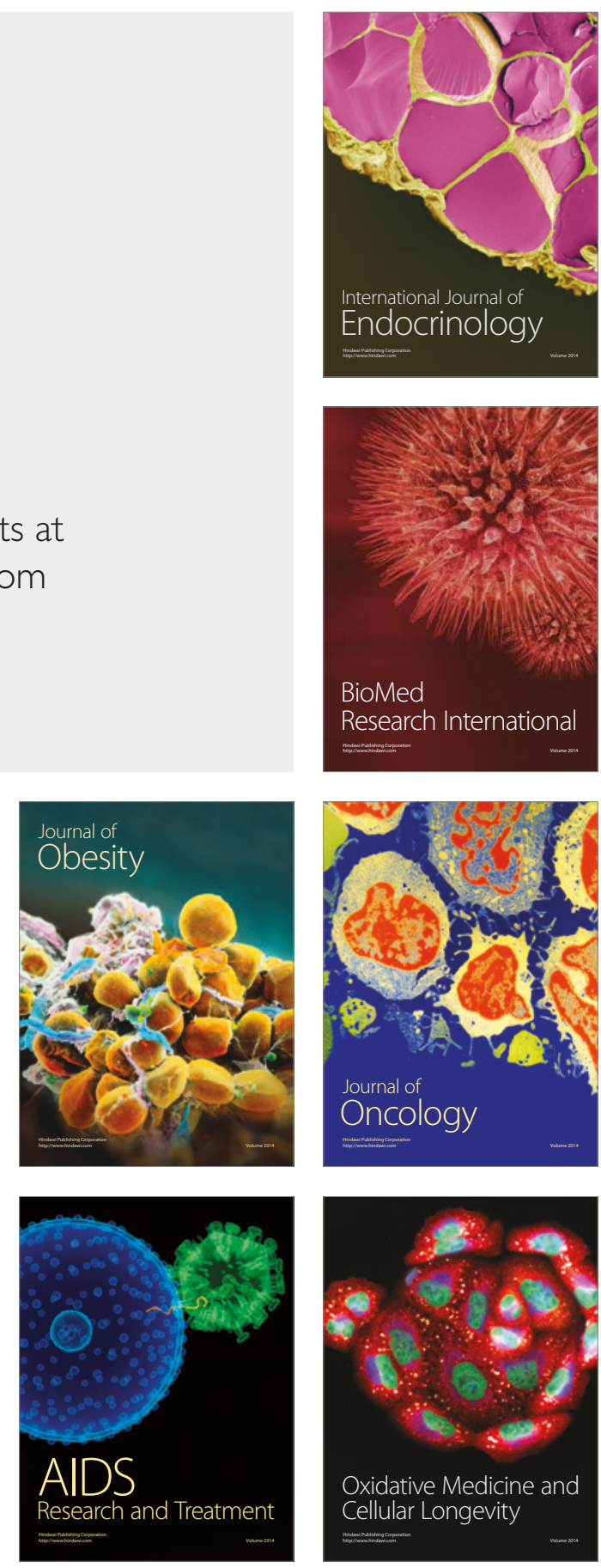